\title{
Possibility of normokalaemic primary aldosteronism as reflected in the frequency of adrenal cortical adenomas
}

\author{
I. DÉVÉNYI \\ From the Department of Pathology, University Medical School, Debrecen, Hungary
}

SYNOPSIS Adrenal cortical adenomas with diameters greater than $3 \mathrm{~mm}$. were found in $185(3.61 \%$, of 5,120 consecutive necropsies. A progressively higher incidence with increasing age was noted) $82 \%$ of the adenomas occurring in cases in the age range 51-80 years.

On the basis of age distribution of adenomas and their connexion with hypertension, there does not seem to be sufficient proof to suppose that the cortical adenomas frequently found at necropsy can be held responsible for causing normokalaemic primary aldosteronism to the extent assumed by Conn (1964).

Primary aldosteronism has recently been isolated as a surgically curable form of hypertension in work described by Conn (1964), Conn, Cohen, and Rovner (1964), and Conn, Rovner, and Cohen (1965). They say that in about $20 \%$ of cases of essential hypertension there are aldosterone-producing adrenal cortical adenomas but their recognition is impeded by the fact that hypokalaemia, the presence of which is indispensable for the diagnosis, only develops at the later stages of the disease, quite often after a 10-year period of hypertension. Consequently the disease may be regarded in the early stage as essential hypertension. The recognition of these cases of normokalaemic primary aldosteronism would be very important as they represent curable forms of hypertension.

Conn (1964) Conn et al. (1964), and Conn, Cohen, Rovner, and Nesbit (1965) have recommended a method for separating cases of normokalaemic primary aldosteronism from those of essential hypertension. By this means they have succeeded,

Received for publication 9 August 1966. at least in one case up to date, in verifying their hypothesis. In addition, retrospective analysis of their previously observed cases has revealed the frequently delayed manifestation of hypokalaemia.

Since 'non-functioning' adrenal cortical adenomas have been found very frequently at necropsies and since, according to Conn (1964), 20\% of cases of essential hypertension should be classified as normokalaemic primary aldosteronism, necropsy material from this hospital has been evaluated with this diagnosis in mind.

\section{PRESENT ANALYSIS}

Reports of 5,120 consecutive necropsies carried out between 1956 and 1965 were examined $(2,351$ on females, 2,769 on males). The age distribution of cases is shown in Table $I$.

All cortical nodules with diameters greater than $3 \mathrm{~mm}$. were considered to be adenomas, except for the yellow foci of spotted lipid depletions. Adrenal cortical adenomas were noted in 185 of the 5,120

TABLE I

AGE DISTRIBUTION IN 5,120 NECROPSIES AT THE DEPARTMENT OF PATHOLOGY, UNIVERSITY MEDICAL SCHOOL, DEBRECEN

\begin{tabular}{|c|c|c|c|c|c|c|c|c|c|c|c|}
\hline \multirow[b]{2}{*}{ Necropsy Groups (\%) } & \multicolumn{11}{|c|}{ Age Range (years) } \\
\hline & $0-10$ & $11-20$ & $21-30$ & $31-40$ & $41-50$ & $51-60$ & $61-70$ & $71-80$ & $81-90$ & $91-100$ & Total \\
\hline $\begin{array}{l}\text { Females } \\
\text { Males } \\
\text { Total } \\
\text { Total number }\end{array}$ & $\begin{array}{r}31 \cdot 2 \\
30 \cdot 5 \\
30 \cdot 8 \\
1,581\end{array}$ & $\begin{array}{r}2 \cdot 6 \\
2 \cdot 2 \\
2 \cdot 4 \\
124\end{array}$ & $\begin{array}{r}3 \cdot 3 \\
2 \cdot 3 \\
2 \cdot 7 \\
143\end{array}$ & $\begin{array}{r}6 \cdot 3 \\
5 \cdot 1 \\
5 \cdot 7 \\
292\end{array}$ & $\begin{array}{c}9.0 \\
9.0 \\
9 \cdot 0 \\
463 \\
49\end{array}$ & $\begin{array}{l}12 \cdot 4 \\
17 \cdot 5 \\
15 \cdot 2 \\
782\end{array}$ & $\begin{array}{l}18 \cdot 9 \\
18 \cdot 4 \\
18 \cdot 6 \\
956\end{array}$ & $\begin{array}{r}13 \cdot 2 \\
11 \cdot 5 \\
12 \cdot 3 \\
632\end{array}$ & $\begin{array}{r}2 \cdot 7 \\
2 \cdot 7 \\
2 \cdot 7 \\
141\end{array}$ & $\begin{array}{l}0 \cdot 04 \\
0 \cdot 1 \\
0 \cdot 1 \\
6\end{array}$ & 5,120 \\
\hline
\end{tabular}


TABLE II

INCIDENCE OF ADRENAL CORTICAL ADENOMAS IN 5,120 NECROPSIES

Age Range (years)

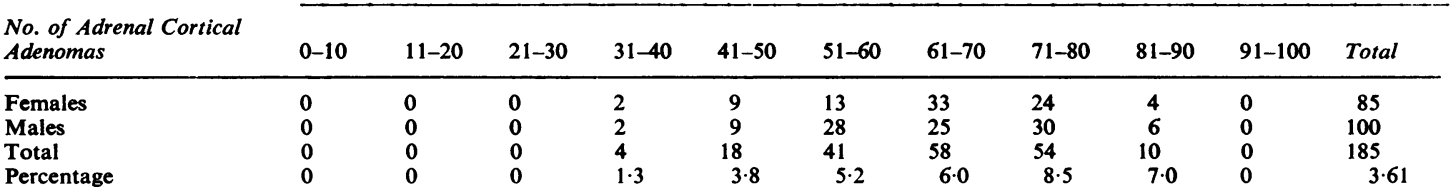

TABLE III

INCIDENCE OF 185 ADRENAL CORTICAL ADENOMAS GROUPED ACCORDING TO AGE AND TYPE OF HYPERTENSION

\begin{tabular}{|c|c|c|c|c|c|c|c|c|c|c|c|}
\hline $\begin{array}{l}\text { Age Range } \\
\text { (years) }\end{array}$ & $\begin{array}{l}\text { Essential } \\
\text { Hyper- } \\
\text { tension }\end{array}$ & $\begin{array}{l}\text { Renal } \\
\text { Hyper- } \\
\text { tension }\end{array}$ & $\begin{array}{l}\text { Conn } \\
\text { Syndrome }\end{array}$ & $\begin{array}{l}\text { Cushing's } \\
\text { Disease }\end{array}$ & $\begin{array}{l}\text { Malignant } \\
\text { Tumour } \\
\text { with } \\
\text { Hyper- } \\
\text { tension }\end{array}$ & $\begin{array}{l}\text { Brain } \\
\text { Tumour } \\
\text { with } \\
\text { Hyper- } \\
\text { tension }\end{array}$ & $\begin{array}{c}\text { Brain } \\
\text { Tumour }\end{array}$ & $\begin{array}{l}\text { Malignant } \\
\text { Tumour }\end{array}$ & $\begin{array}{l}\text { Valvular } \\
\text { Heart } \\
\text { Disease or } \\
\text { Cor } \\
\text { Pulmonale }\end{array}$ & Miscellaneous & Total \\
\hline $\begin{array}{l}31-40 \\
41-50 \\
51-60 \\
61-70 \\
71-80 \\
81-90 \\
\text { Total }\end{array}$ & $\begin{array}{r}0 \\
2 \\
9 \\
13 \\
27 \\
4 \\
55\end{array}$ & $\begin{array}{r}1 \\
0 \\
2 \\
6 \\
2 \\
0 \\
11\end{array}$ & $\begin{array}{l}0 \\
11 \\
0 \\
0 \\
0 \\
0 \\
1\end{array}$ & $\begin{array}{l}1 \\
0 \\
0 \\
1 \\
0 \\
0 \\
2\end{array}$ & $\begin{array}{l}0 \\
0 \\
1^{2} \\
1^{2} \\
0 \\
0 \\
2\end{array}$ & $\begin{array}{l}0 \\
2 \\
2 \\
0 \\
0 \\
0 \\
4\end{array}$ & $\begin{array}{l}0 \\
3 \\
2 \\
1 \\
0 \\
0 \\
6\end{array}$ & $\begin{array}{r}0 \\
3 \\
8 \\
16 \\
8 \\
2 \\
37\end{array}$ & $\begin{array}{r}0 \\
2 \\
8 \\
11 \\
7 \\
1 \\
29\end{array}$ & $\begin{array}{r}2 \\
5 \\
9 \\
9 \\
10 \\
3 \\
38\end{array}$ & $\begin{array}{r}4 \\
18 \\
41 \\
58 \\
54 \\
10 \\
185\end{array}$ \\
\hline
\end{tabular}

necropsy reports (85 females, 100 males). Sixty-two per cent of adenomas had diameters of 1 to $2 \mathrm{~cm}$., $77.3 \%$ were unilateral and solitary, $2.7 \%$ were unilateral and multiple, $14.6 \%$ were bilateral and solitary, and $5.4 \%$ were bilateral and multiple (Table II).

Eighty-two per cent of the adenomas belonged to cases in the age range 51-80 years.

Table III shows the data of cases with adenomas classified according to age and to hypertension and fatal illness. The ascertainment of hypertension was based on clinical data, heart weight, condition of the kidneys, and other necropsy data.

\section{COMMENT}

Analysing our observations, the frequency and age distributions of adenomas correspond with the investigations of other authors carried out with similar criteria (Commons and Callaway, 1948).

It is not the purpose of this study to analyse the relation between hypertension and cortical adenoma, although, after looking through the records without any statistical evidence, it has been our impression that the frequency of adenoma seems to be influenced mostly by age. In the pertinent literature there are numerous opinions emphasizing the close connexion between cortical adenomas and essential hypertension (Rinehart, Williams, and Cappeller, 1941;
Dawson, 1956; Fassbender, 1956; Shamma, Goddard, and Sommers, 1958; Sherwin, 1964), although other authors have denied such a connexion (Commons and Callaway, 1948).

The criteria of differentiating between cortical adenoma and nodular hyperplasia have not yet been defined. The arbitrary classification applied by us is fundamentally unsuitable but we have applied it because, according to Conn, Knopf, and Nesbit (1964), who have analysed 145 cases of the Conn syndrome, the lower size limit of adenomas was similar. According to Conn et al., 'It is worthy of emphasis that the great majority of these tumours are small and that failure to visualize them by the various technics now in vogue does not exclude their presence." In the same material there were multiple aldosteronomas in $9 \%$ of cases. Recently Cohen (1966) assumed that hyperplastic cortical nodules may be precursors of adenomas, and they are similar from a functional and histochemical point of view.

Summarizing 145 cases of primary aldosteronism, Conn et al. (1964) established that $72 \%$ of the patients belonged to the age range $31-49$ years at the ? time of operation, and consequently with illnesses existing for some time. The $20 \%$ of cases of essential hypertension considered by Conn (1964) as of 'latent' primary aldosteronism should be expected to be by far the greatest number in the same age 
range. On the contrary, in our material, $82 \%$ of adenomas belonged to cases in the age range $51-80$ years. Only $11.8 \%$ of the adenomas belonged to cases in the age range 31-50 years, characteristic of primary aldosteronism.

Of the 22 adenomas from cases in the $31-50$ age range, only seven were found to involve simultaneous hypertension (Table III). Among these cases there was one of the genuine Conn syndrome, with hypokalaemic nephropathia, one of Cushing's disease, two cases of brain tumour with hypertension, and one of renal hypertension.

As may be seen, there are only two cases of cortical adenoma with coexistent essential hypertension, in which the diagnosis of normokalaemic primary aldosteronism is possible.

From our 755 necropsy cases in the age range 31-50 years (Table I) 7\% were of hypertension. Among these, $2.6 \%$ were of essential hypertension cases (renal hypertension $3.1 \%$, brain tumour with hypertension $0.8 \%$, malignant tumour with hypertension $0.4 \%$ ). At the same time, the two cases of cortical adenoma with coexistent essential hypertension represent $0.26 \%$ of the 755 cases. It follows that among the essential hypertension cases from the age range 31-50 years, according to our necropsy material, the incidence of normokalaemic primary aldosteronism might not be more than $10 \%$ $(2.6: 0.26)$. This maximal value is only half of the number suggested by Conn (1964). It does not seem sufficient material to suppose that in the post-mortem room the finding of frequently occurring 'nonfunctioning', 'incidental' cortical adenomas are to be held responsible for causing normokalaemic primary aldosteronism to such a great extent as has been supposed by Conn (1964).

\section{REFERENCES}

Cohen, R. B. (1966). Cancer (Philad.), 19, 552.

Conn. J. W. (1964). J. Amer. med. Ass., 190, 222.

_, Cohen, E. L., and Rovner, D. R. (1964). Ibid., 190, 213.

,,,--- , and Nesbit, R. M. (1965). Ibid., 193, 200.

- Rovner, D. R., and Cohen, E. L. (1965). Ann. intern. Med. 63, 266.

—, Knopf, R. F., and Nesbit, R. M. (1964). Amer. J. Surg., 107, 159.

Commons, R. R., and Callaway, C. P. (1948). Arch. inter. Med., 81, 37.

Dawson, I. M. P. (1956). J. Path. Bact., 72, 393.

Fassbender, H. G. (1965). Pathologische Anatomie der endokrinen Drüsen. In Staemmler M. Lehrbuch der speziellen pathologischen Anatomie, 11 th and 12 th ed., Bd. 1, Hälfte 2. W. de Gruyter, Berlin.

Rinehart, J. F., Williams, O. O., and Cappeller, W. S. (1941). Arch. Path., 32, 169.

Shamma, A. H., Goddard, J. W., and Sommers, S. C. (1958). J. chron. Dis., 8, 587

Sherwin, R. P. (1964). Amer. J. Surg., 107, 136. 